\title{
Bureaucrats' processing of organizational reputation signals
}

\section{Sharon Gilad*, Pazit Ben-Nun Bloom†, Michaela Assouline ${ }^{\ddagger}$}

\begin{abstract}
Notwithstanding the significance of a positive bureaucratic reputation, the average bureau functions amidst deep-rooted public hostility. Bureaucracy bashing presumably weakens public sector employees' commitment to their bureaus, which is known to undermine public sector performance. Motivated by these concerns, this paper investigates whether exogenous signals regarding a bureau's reputation affect the organizational attachment - identification and commitment - of its employees, and the variation in employee responses. Employing an experiment at an Israeli welfare bureaucracy, we show that the organizational attachment of employees who feel central and influential within the bureau is unshaken, and even reinforced, in response to negative reputation signals. Conversely, employees who feel marginal and powerless are receptive to both negative and positive reputation signals. The implications of these findings are that public organizations can buffer their employees from the detrimental effects of negative reputation signals, yet by so doing they may shut out justified scrutiny and demands for change.
\end{abstract}

Keywords: Bureaucratic reputation, Reputation signals, Organizational identification, Organizational commitment

$\mathrm{O}$ ccupation and career are central to how we evaluate ourselves and one another. We therefore seek to associate ourselves with occupations and workplaces that reflect positively on our social standing and self-esteem. Public bureaus and their employees, however, are burdened by deeprooted public hostility and by political and media bashing (Goodsell, 1994; Hvidman \& Andersen, 2015; Marvel, 2015, 2016; Del Pino et al., 2016). Extant management research would suggest that negative reputation signals may lead employees to withdraw their identification with their bureaus, and commitment to them, resulting in lower individual and organizational performance. Despite the

* Department of Political Science \& the Federmann School of Public Policy and Government, The Hebrew University of Jerusalem;

† Department of Political Science, The Hebrew University of Jerusalem;

‡ Department of Political Science, The Hebrew University of Jerusalem \& The National Social Security Institute

Address correspondence to Sharon Gilad at (sharon.gilad@mail.huji.ac.il)

Copyright: (C) 2018. The authors license this article under the terms of the Creative Commons Attribution 4.0 International License. gravity of these concerns, within the public management literature the implications of entrenched negative bureau reputations for the attitudes and behaviors of public sector employees are rarely discussed (Chen \& Bozeman, 2014; Garrett et al., 2006). Moreover, the few studies that analyze the consequences of bureaucracy bashing for employees fail to examine endogenous mechanisms that public organizations might use to secure employees' attachment and contributions.

To advance the limited research in this domain, we delineate a theoretical model, which stresses the contingent effects of reputation signals on public-sector employees' organizational identification and commitment. Building on Carpenter (2010), we treat reputation signals as expressions of external audiences' views of a bureau, relating to its performance, technical expertise, procedural legality, or morality. We argue that reputation signals, which reveal the public's disregard for a bureaucratic organization, do not universally undermine its employees' organizational identification and commitment. Employees who derive high self-esteem from their perceived competence and value within the organization, are relatively buffered from the effect of exogenous reputation signals. Employing a survey experiment, we test these propositions in the context of an Israeli welfare agency. 


\section{Bureaucratic Reputation and Employees' Organizational Attachment}

Organizational Identification (Riketta, 2005) and Organizational Commitment (Meyer et al., 2002) are two facets of organizational attachment. Organizational commitment received substantial attention in public management research (e.g. Bullock et al., 2015; Chordiya et al., 2017; Dick, 2011; Hassan \& Rohrbaugh, 2012; Lyons et al., 2006; Moldogaziev \& Silvia, 2015; Moynihan \& Pandey, 2007; Stazyk et al., 2011; Tummers \& Knies, 2013; Yang \& Pandey, 2009), whereas organizational identification has been relatively overlooked (cf. Rho et al, 2015). The salience of both concepts, in organizational studies, lays in their documented correlations, albeit to different degrees, with significant outcomes, including employees' absenteeism, job involvement, voluntary contributions, overall job and organizational satisfaction and intentions to leave (Meyer et al., 2002; Riketta, 2005).

Organizational identification regards an individual's categorization of herself as a member of an organization, and of the organization as central to her self-concept (Ashforth \& Mael, 1989; Haslam \& Ellemers, 2005). As such, the theorization of organizational identification is rooted in Social Identity Theory, according to which individuals' self-concept is based on their self-linkage to multiple social groups and organizations, with some identities being more salient than others given situational factors and contextual cues (Tajfel, 1982).

Organizational commitment is a broader, less distinct, concept, encompassing three elements of one's attachment - staying in the organization due to positive affect (affective commitment), sense of obligation (normative commitment), or lack of alternatives (continuance commitment) (Allen \& Meyer, 1990; Van Dick, 2004). In this study, we focus on employees' affective organizational commitment, which has been shown to exert the strongest, and most constructive, effects on employees' attitudes and behaviors (Mathieu \& Zajac, 1990; Meyer \& Allen, 1997; Meyer et al., 2002).

Our introduction hinted at the dearth of research about the consequences of bureaus' reputations for employees' organizational attachment, or indeed for any type of attitudes or behaviors. Garrett et al. (2006) conducted focus groups with senior civil servants who indicated that bureaucracy bashing in electoral campaigns impaired their morale, undermined bureau recruitment and fueled distrust between civil servants and political appointees. More recently, Chen and Bozeman's (2014) survey-based study found that public sector managers tend to internalize the public's perceptions of private sector superiority, resulting in lower reported levels of job involvement, job satisfaction, and pride in being members of their bureaus.

Alongside the above scarcity in public administration studies, a sizeable body of non-experimental, survey-based organizational research suggests that employees' beliefs about their organizations' external image is positively associated with organizational identification (e.g. Bartels et al., 2007; Dukerich et al., 2002; Dutton et al., 1994; Fulller et al., 2006; Riketta, 2005; Rho et al., 2015; Smidts et al., 2001) and commitment (Carmeli, 2005; Carmeli \& Freund, 2009). Building on social identity theory, this literature suggests that employees are inclined to adopt highly-regarded organizations as central to their self-concept, over other potential identities (e.g., other organizations or social groups), because this reflects positively on their self-esteem (Meyer et al., 2006).

For public organizations, the above literature implies that negative public sentiment and bureaucracy bashing may undermine employees' organizational attachment, with detrimental behavioral consequences. Still, we cannot draw reliable inferences from current research, since organizational image, as conceptualized and measured in these studies, regards employees' subjective beliefs about external audiences' perceptions of their organizations. The patent flaw in extant research pertains to its overlook of the possible endogeneity between the dependent variables - employees' organizational identification and commitment - and employees' construction of the organization's image. Employees who have incorporated the bureau as central to their self-concept are presumably motivated to believe that external audiences value their organization, because such a belief allows them to maintain positive self-esteem. As Chen and Bozeman (2014, p. 561) acknowledge, overcoming this shortfall entails an experimental manipulation of employees' perceptions of how external audiences perceive their organization. Hence, the first goal of this paper is to assess whether positive and negative reputation signals, which are independent of employees' self-construction of the organization's image, in fact shape their organizational attachment. Specifically, we hypothesize that: 
$H_{1 a-b:}$ Negative (/positive) reputation signals are negatively

(/positively) associated with an employee's identification with, and commitment to, the organization.

\section{Organization-based Self-esteem as a Moderator of Reputation Signals}

Our above hypothesis suggests that bureaucratic reputation, due to its consequences for employees' derivation of self-esteem from organizational membership, likely shapes their organizational identification and commitment. Still, we propose that public sector organizations and their managers can regulate the effect of reputation signals on employees by enhancing (or undermining) employees' perceptions of themselves as competent and valued within the organization.

An extensive body of research shows that employees' perceptions of themselves as competent, influential, and important within the organization (Bowling et al., 2010), tagged Organizational-Based SelfEsteem (OBSE), are shaped by intra-organizational factors. This includes organizational and job structures that allow employee participation and discretion, encouraging messages from significant others (e.g., supervisors) and on-the-job experiences of success and failure (Pierce \& Gardner, 2004). Prior studies have confirmed a strong, positive, association between OBSE and both organizational identification, and affective organizational commitment (Bowling et al., 2010; Pierce \& Gardner, 2004).

In addition to its established direct effect, we expect employees' OBSE to moderate the effect of reputation signals on their organizational identification and commitment. Employees who feel competent, influential, and important within their bureau are potentially more threatened by negative reputation signals. This is so because such signals conflict with a key grounding and dimension of their self-esteem and self-concept. Related organizational research documents employees' response to such identity threats. It suggests that committed employees working in "dirty occupations" (Ashforth et al., 2007), or condemned organizations (Gendron \& Spira, 2010), tend to guard their identities through an array of strategies including adherence to occupational ideologies that explain away external allegations as misguided, maintaining high social cohesion and/or defensive derogation of those who are making the accusations (e.g.,
Petriglieri, 2011). Consequently, we expect employees who enjoy high OBSE to dispute the veracity and impartiality of negative reputation signals. The identity threat posed by negative external signals may accentuate these employees' perception of us (bureau members) versus them (the ignorant public, self-serving politicians, and biased media) and paradoxically may enhance their organizational identification and commitment.

Alternatively, a related psychological mechanism implies that employees who enjoy high self-esteem from organizational membership would be unaffected by external reputation signals, regardless of their content. Given their strong incentive to maintain a positive image of their organization, such employees are incentivized to accumulate information that supports their favorable image of the organization and to rehearse defense of their workplace. Well-rehearsed attitudes form strong and stable associations between objects and evaluations which are automatically activated (e.g., Fazio, 2001; Fazio et al., 1986). Such entrenched associations between their organization and positive evaluations may render employees' attitudes impervious to the influence of new information, whether positive or negative.

Turning to employees at the low end of OBSE, extant research would expect the bureau to be relatively peripheral to these employees' selfconcept, given their feeling of marginalization within the organization. As such, they are less psychologically invested in a positive image of the organization and of their own work within it. We would therefore expect them to be more open to external direction and less judgmental of the veracity and impartiality of external signals, which neither threaten nor reinforce a central dimension of their individual identity and self-esteem. Thus, their beliefs about the organization and how others view it, and thereby their organizational identification and commitment, may be more malleable to the influence of external signals. Negative reputation signals would convey to employees that external audiences have a negative view of their organization, undermining their already low derivation of self-esteem from organizational membership, leading to an even lower organizational attachment. Positive signals, conversely, would improve these employees' perceptions of the organization's image, providing an external source of self-esteem from organizational membership and thereby boost their generally low organizational attachment. Thus, we 
propose:

$H_{2 a-b}$ : The effect of reputation signals is moderated by organizational-based self-esteem, such that the detrimental (/ advantageous) effect of negative (/ positive) reputation signals on organizational attachment wanes as employees enjoy bigher organizational-based self-esteem.

\section{Methodology}

\section{Research Design}

Our research focuses on the organizational identification and commitment of employees of the Israeli National Social Security Institute (NSSI). The NSSI is a statutory organization, employing around 3,800 employees. NSSI provides all Israeli citizens with a basic, mandated pension and manages citizens' claims for means-tested benefits for disability, unemployment and income support, among others.

We conducted our research in July 2016 simultaneously in four of the NSSI's 23 branch offices at the cities of Jerusalem, Tel Aviv, Beer Sheva and Rehovot. ${ }^{1}$ We selected these four offices for their relatively large employee numbers and for their non-extreme values as revealed from a confidential NSSI's client satisfaction survey. ${ }^{2}$ Permission to conduct the study at the NSSI branches was granted by the organization's chief HR director, the branches' heads and local HR managers. The study was subject to ethical review and authorization by Hebrew University's IRB committee. Three trained research assistants, supervised by the third coauthor who works for the NSSI's research department, distributed surveys in the relevant offices to consenting participants and collected them within about an hour of their distribution.

Participants were randomly assigned to one of three versions of our survey ${ }^{3}$ employing a between-subjects, non-factorial design. ${ }^{4}$ All surveys opened with an identical set of Likert-item questions, including questions about employees' OBSE, additional demographics and controls. Following these survey questions, two groups of respondents read and were primed with one of two versions of an experimental manipulation $(\mathrm{N}=62$ and $\mathrm{N}=51)$. The third control group received a manipulationfree survey $(\mathrm{N}=52)$. All participants were then asked identical survey items regarding their organizational identification and commitment.

\section{Manipulation and Operationalization of Variables}

The experimental manipulation, which provided respondents with an external signal of the NSSI's reputation, involved equivalent positive and negative framing (as in Olsen, 2015) of the findings of a real academic study (Mizrahi et al., 2010). The control group received no reputation signal. Our negative and positive reputation signal conditions read as follows (bold and underline in the original):

"Towards conclusion, we would like to allow you to convey, in your own words, how you experience the relationship between the NSSI and the insured ${ }^{5}$ public.

In research conducted by the universities of Haifa and Ben-Gurion, funded by the NSSI, citizens were asked about their trust in the Institute $^{6}$ and its employees.

Around $50 \%$ of the insured who participated in the study reported that they [have no trust / trust] in the National Social Security institute.

In the available space [below], tell us about an experience in which you encountered, personally or via the media, the public's [mistrust/ trust] of the NSSI, and how you felt at that moment."

The logic underlying the above manipulations is that organizational identification, like other forms of social identity, is malleable and open to external cues (cf. Benjamin et al., 2016; Ben-Nun Bloom et al., 2015; Cohn et al., 2014).

Our measurement of Organizational Identification, which appeared immediately following the manipulations, involved translation of three items (Cronbach's alpha $=0.82$ ) from an index developed by Mael and Ashforth (1992). A representative item from this index is "When talking to family and friends about the NSSI's employees, I tend to say 'we' and not 'them'."

Appearing following the manipulations, our operationalization of Affective Organizational Commitment drew on four items (Cronbach's alpha $=0.78)$ from a validated index developed by Allen and Meyer (1990). Representative items from this index include "the NSSI is very meaningful for me," or "the thought that I would be working at the NSSI until retirement pleases me." 
Our measurement of OBSE is a translation of a six-item index (Cronbach's alpha $=0.87$ ), developed by Pierce et al. (1989). A representative item is "my opinion is important in this workplace."

To facilitate interpretation of the relative effects of the variables, we normalized all measurements to range between zero and one. The appendix presents descriptive statistics for the sample and for each of the three experimental groups, as well as a full translation of the above survey indices.

\section{Results}

The multivariate analysis in Table 1 tests the effects of the manipulated negative and positive reputation signals of NSSI's reputation versus the baseline of the control group, on employees' organizational commitment (Models I-Va) and identification (Models I-Vb). First, in accordance of $\mathrm{H}_{1 \mathrm{a}-\mathrm{b}}$ we assess the independent effects of the positive and negative manipulated reputation signals (Models Ia \& Ib). Then, in line with $\mathrm{H}_{2 \mathrm{a}-\mathrm{b}}$, we estimate OBSE as a moderator of the effect of both the positive and the negative reputation signals by specifying interactions between these two terms (Models II-Va \& II-Vb). We present both the bare-bone models (I-IIa \& I-IIb, IVa \& IVb), including just the experimental treatments and OBSE, as well as the models using control variables (IIIa \& IIIb, Va \& Vb), holding constant employee demographics and fixed effects for the NSSI local branches as additional robustness checks.

Table 1

The interactive effect of reputation signals and organizational-based self-esteem on organizational commitment and identification - Experiment

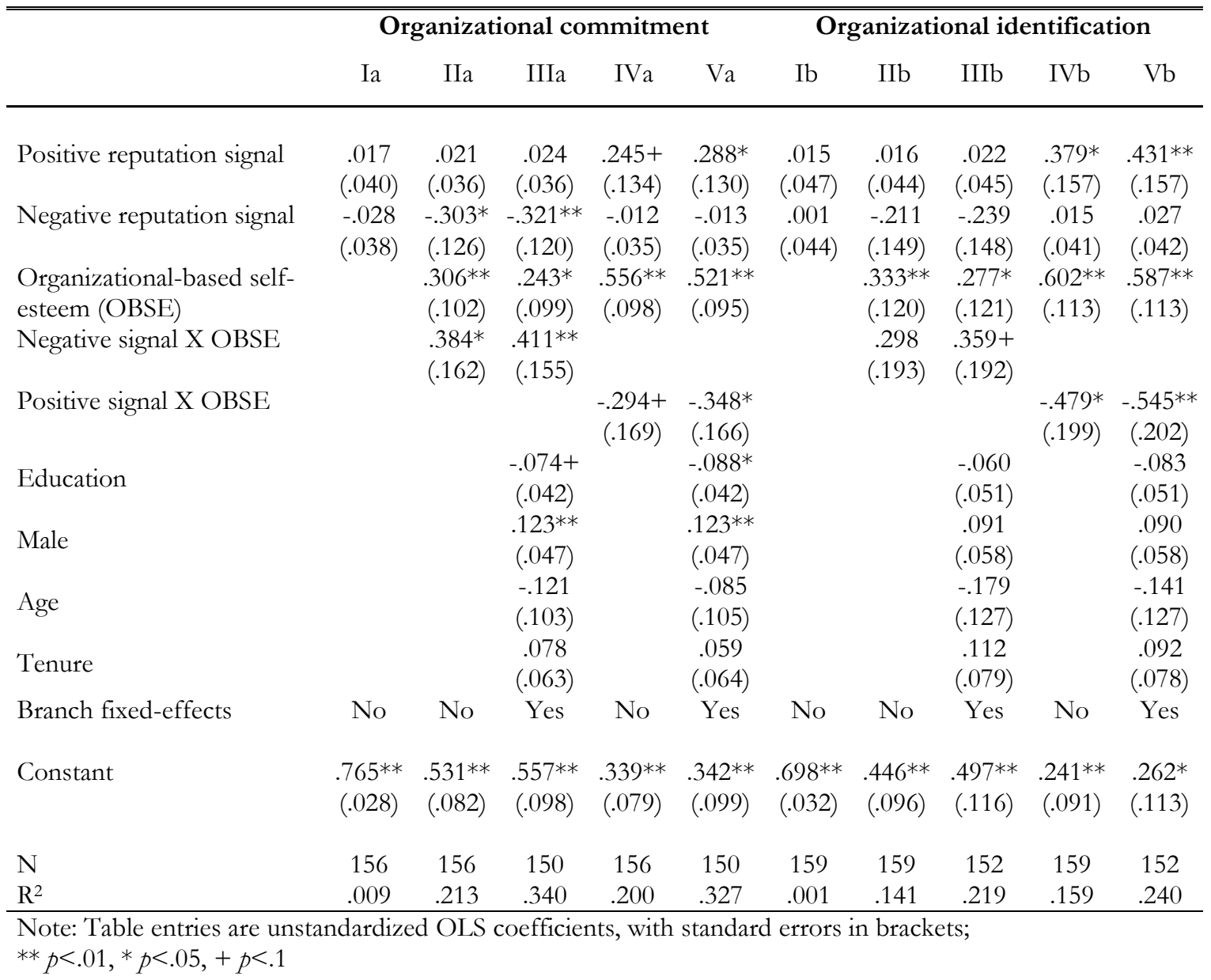


Counter to the expectations of $\mathrm{H}_{1 \mathrm{a}-\mathrm{b}}$, the manipulated negative and positive signals of the NSSI's reputation had no significant effect on employees' organizational commitment (Model Ia) and identification (Model Ib), compared with the control condition. In addition, comparing the positive and negative reputation signals with each other directly (not presented in Table 1) yielded no statistically significant effects ( $\mathrm{pOC}=.240$, $\mathrm{p}_{\mathrm{OI}}=.742$ ).

While we find no evidence for the direct effects of reputation signals (Models Ia and Ib), seven of the possible eight treatment-by-OBSE interactions - in both the controlled and uncontrolled models, and for both dependent variables - allow rejecting the null hypothesis for $\mathrm{H}_{2 \mathrm{a}-\mathrm{b}}$, showing the expected moderation trend. ${ }^{7}$

Figure 1 depicts the marginal effects for the four interactions between the reputation signals and OBSE. That is, the changes in the effect of each of the two reputation signals across the observed range of OBSE. The upper panels depict the marginal effect of the negative and positive signals on organizational commitment (corresponding to Models IIIa and Va, respectively), and the lower panels - on organizational identification (Models IIIb and $\mathrm{Vb}$ ).

Starting with the left-hand side panels of Figure 1, the interactions indicate that exposure to a negative reputation signal, relative to the control condition, has a diminishing effect on organizational commitment and identification of employees, which declines and reverses as employees' OBSE increase. These results accord with $\mathrm{H}_{2 a}$. Specifically, the negative effect of the reputation cue on organizational commitment was significant at the $95 \%$ level among employees holding low to medium levels of OBSE - equal to, or smaller than, .58 on a 0 1 scale ( $15 \%$ of the sample) - and at least marginally significant under OBSE levels of .62 ( $\mathrm{p}<.1,24 \%$ of

\section{Figure 1}

\section{The marginal effect of the reputation signals by level of OBSE on organizational commitment and identification}
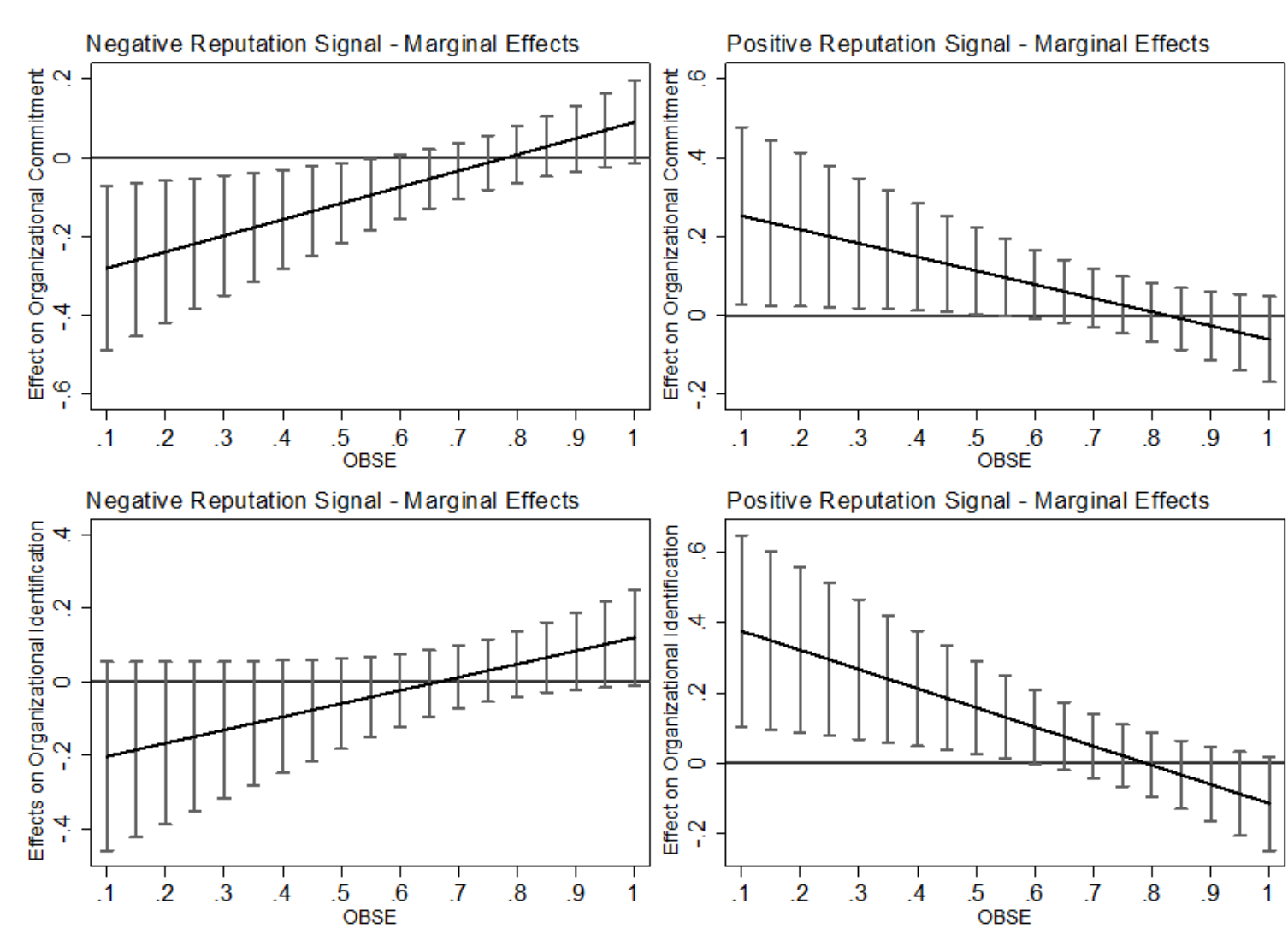
the sample). The opposite effect, indicating a backlash effect of negative reputation signals on organizational commitment, emerges at a $10 \%$ significance level for employees at the highest $2-3 \%$ of OBSE scale ( $p<.1,5.5 \%$ of the sample). Whereas this trend replicates for organizational identification, the negative effect of the negative reputation signal at the low level of OBSE does not reach conventional levels of statistical significance, whereas the backlash effect at the high level of OBSE is significant at a $10 \%$ level above an OBSE level of 0.92 , which relates to $15 \%$ of the sample.

Moving to the positive reputation signal presented in the right-hand side panels, the effects of the signal at the minimum level of OBSE overturns as hypothesized $\left(\mathrm{H}_{2 \mathrm{~b}}\right)$. When OBSE is at the low to medium levels (organizational commitment: $\mathrm{p}<.1$ min to 0.63 ; organizational identification: $\mathrm{p}<.1$ min to $0.64 ; 27 \%$ of the sample), employees' organizational commitment and identification increase when exposed to the positive reputation signal relative to the control condition. For employees at the highest level of OBSE, in line with our expectations, exposure to the positive reputation signal had no significant effect on organizational commitment at any level, but it did however have a statistically significant negative effect on organizational identification when OBSE is at its maximum level of $1\left(b=-.114, p=.092,5 \%\right.$ of the sample) ${ }^{8}$

\section{Discussion and Conclusion}

Public administration scholars assert that a positive organizational reputation is a requisite for bureaucratic success, autonomy, and power (Alon-Barkat \& Gilad, 2016; Busuioc \& Lodge, 2015, 2017; Carpenter, 2010; Carpenter \& Krause, 2012; Gilad et al., 2015, 2016; Maor, 2015; Maor et al., 2013). Yet, constructing a positive bureaucratic reputation is an uphill battle given the public's mistrust in the public sector (e.g. Marvel, 2015, 2016) and bureaucracy bashing by politicians and the media. The assumption of extant research is that bureaucracies' often negative reputations may undermine their performance, inter alia due to the detrimental effect for employee morale and commitment. Employing an experimental manipulation, this paper sought to estimate the effect of negative and positive reputation signals on public sector employees' organizational attachment, and its moderation by employees' derivation of self-esteem from feeling valued and important within the organization (OBSE).

To the best of our knowledge, ours is the first study to assess the effect of an experimental manipulation of employees' perceptions of external audiences' views of the organization on employees' organizational identification and commitment. Experimentally manipulating reputation signals - rather than measuring perceived organizational image, as is the rule in extant research - is important, given that there is likely a reciprocal influence (endogeneity) between employees' organizational identification and commitment and their construction of the organization's image.

Contrary to our expectations and those of extant survey-based research, we found no independent effect to the positive or negative reputation signals on employees' organizational attachment. Yet as expected, our findings confirm that employees' OBSE fully conditions their reactions to external signals regarding the bureau's reputation. For employees who feel marginal and powerless within the organization, external reputation signals provided a relevant cue for the bureau's reflection on their image as individuals, shaping their inclination to adopt or reject the organization as part of their self-concept and to commit to it.

Conversely, external reputation signals had little consequences for the organizational attachment of employees who blossom under intra-organizational structures and dynamics that communicate high regard for their contributions. If anything, these employees seem to reject the veracity and impartiality of negative reputation signals, rendering their organizational identification and commitment even more salient.

The key implication of our findings is that employees' longing to feel valued and esteemed within the organization regulates their response to external reputation signals. Consequently, senior managers can mitigate, and even offset, the detrimental effects of a negative bureaucratic reputation through organizational processes and interfaces that signal the value that they and the organization attribute to employees' competence and contributions. These findings provide an important and hopeful message for those who believe that public sector organizations are unduly burdened by negative reputations despite their generally decent performance. Still, a potential concern raised by our findings is that employees' derivation of high self- 
esteem from feeling important and valued within the organization may buffer themselves and public organizations from adaptation to politicians and the public's expectations and demands for change.

These contributions notwithstanding, we acknowledge the limitations of our study. First, our conclusions draw on findings derived from one Israeli organization, calling for replication in other organizations and countries, possibly employing a stronger manipulation of the organization's positive and negative reputations. Second, our moderate, one-off, manipulations of the NSSI's reputation are likely to have created no more than a transitory effect on employees' organizational identification and commitment. Still, we believe that the effects that we have shown are suggestive of the operation of OBSE as a buffer to employees' cumulative exposure to real-world reputation cues via media coverage, and daily interactions with family, friends and clients. That said, our experiment did not include a manipulation check and we are therefore unable to empirically rule out the possibility that the null main effects are due to the subtle nature of the manipulations or to the relatively small sample size. Still, the fact that the expected significant effect did emerge within the subset of employees with low OBSE and that our group sizes (over 50 respondents in each group) are not atypical of similar experimental studies somewhat attenuate these concerns. Third, future research may seek to further unravel the micro-mechanisms underlying the moderating effect of OBSE. We suggested two possible micro-mechanisms. One offers that employees, who feel central, valued, and influential within the organization reject the veracity and impartiality of signals that threaten their identity and self-esteem. A second explanation suggests that employees' OBSE regulates the strength of association between the organization and entrenched positive attitudes. Whichever the case, this study points to the scarcity and importance of further research regarding the effects and moderation of reputation signals on public sector employees' attitudes and behaviors.

\section{Acknowledgement}

The authors thank Saar Alon-Barkat, Noam Brenner and Chagai Weiss for their assistance in carrying out this research.

\section{Notes}

1. For technical reasons, surveys in Rehovot were distributed two days after their distribution in the three other branch offices.

2. Two branches had above average and two had below average customer satisfaction scores.

3. In each branch, one research assistant manually distributed the surveys to all present employees who were at their rooms and desks handing the different versions in sequence, so that if one employee received version 1, the person sitting in the desk or room next to her received version 2 and so forth.

4. Two additional treatment groups of different respondents who were exposed to manipulations of their OBSE are omitted from this paper.

5. "The insured" is NSSI internal jargon for citizens/clients.

6. "The Institute" is how employees refer internally to the NSSI.

7. Although as indicated in Table 1, the statistical significance was significant at a $10 \%$ level in two of the models ( $\mathrm{p}_{\mathrm{IVa}}=.085, \mathrm{p}_{\mathrm{IIIb}}=.064$ ).

8. This unexpected finding may reflect the moderate nature of our positive manipulation, which suggested to employees that $50 \%$ of Israelis have high trust in the NSSI. Employees with very high OBSE may have assumed higher levels of citizen support and were therefore negatively primed by the positive manipulation.

\section{References}

Allen, N. J., \& Meyer, J. P. (1990). The Measurement and Antecedents of Affective, Continuance and Normative Commitment to the Organization. Journal of Occupational and Organizational Psychology, 63(1), 118.
Alon-Barkat, S., \& Gilad, S. (2016). Political Control or Legitimacy Deficit? Agencies Symbolic Response to Bottom-Up Public Pressures. Policy \& Politics, 44(1), 41-58. 
Ashforth, B. E., \& Mael, F. (1989). Social Identity Theory and the Organization. Academy of Management Review, 14(1), 20-39.

Ashforth, B. E., Kreiner, G. E., Clark, M. A., \& Fugate, M. (2007). Normalizing Dirty Work: Managerial Tactics for Countering Occupational Taint. Academy of Management Journal, 50(1), 149-174.

Bartels, J., Pruyn, A., De Jong, M., \& Joustra, I. (2007). Multiple Organizational Identification Levels and the Impact of Perceived External Prestige and Communication Climate. Journal of Organizational Behavior, 28(2), 173-190.

Benjamin, D. J., Choi, J. J., \& Fisher, G. (2016). Religious Identity and Economic Behavior. Review of Economics and Statistics, 98(4), 617-637.

Bowling, N. A., Eschleman, K. J., Wang, Q., Kirkendall, C., \& Alarcon, G. (2010). A MetaAnalysis of the Predictors and Consequences of Organization-Based Self-Esteem. Journal of Occupational and Organizational Psychology, 83(3), 601626.

Ben-Nun Bloom P., N. Arikan, G., \& Courtemanche, M. (2015). Religious Social Identity, Religious Belief, and Anti-Immigration Sentiment. American Political Science Review, 109(2), 203-221.

Bullock, J. B., Stritch, J. M., \& Rainey, H. G. (2015). International Comparison of Public and Private Employees' Work Motives, Attitudes, And Perceived Rewards. Public Administration Review, 75(3), 479-489.

Busuioc, E. M., \& Lodge, M. (2015). The reputational basis of public accountability. Governance, 29(2), 247263.

Busuioc, M., \& Lodge, M. (2017). Reputation and Accountability Relationships: Managing Accountability Expectations through Reputation. Public Administration Review, 77(1), 91-100.

Carmeli, A. (2005). Perceived External Prestige, Affective Commitment, and Citizenship Behaviors. Organization Studies, 26(3), 443-464.

Carmeli, A., \& Freund, A. (2009). Linking Perceived External Prestige and Intentions to Leave the Organization: The Mediating Role of Job Satisfaction and Affective Commitment. Journal of Social Service Research, 35(3), 236-250.

Carpenter, D. P. (2010). Reputation and Power: Organizational Image and Pharmaceutical Regulation at the FDA. Princeton, New Jersey: Princeton University Press.

Carpenter, D. P., \& Krause, G. A. (2012). Reputation and Public Administration. Public Administration Review, 72(1), 26-32.

Chen, C. A., \& Bozeman, B. (2014). Am I a Public Servant or Am I a Pathogen? Public Managers 'sector Comparison of Worker Abilities. Public Administration, 92(3), 549-564.

Chordiya, R., Sabharwal, M., \& Goodman, D. (2017). Affective Organizational Commitment and Job
Satisfaction: A Cross-National Comparative Study. Public Administration, 95(1), 178-195.

Cohn, A., Fehr, E., \& Maréchal, M. A. (2014). Business Culture and Dishonesty in The Banking Industry. Nature, 516 (7529), 86-89.

Del Pino, E., Calzada, I., \& Díaz-Pulido, J. M. (2016). Conceptualizing and Explaining Bureauphobia: Contours, Scope, and Determinants. Public Administration Review, 76(5), 725-736.

Dick, G. P. (2011). The Influence of Managerial and Job Variables on Organizational Commitment in the Police. Public Administration, 89(2), 557-576.

Dukerich, J. M., Golden, B. R., \& Shortell, S. M. (2002). Beauty is in The Eye of The Beholder: The Impact of Organizational Identification, Identity, And Image on The Cooperative Behaviors of Physicians. Administrative Science Quarterly, 47(3), 507533.

Dutton, J. E., Dukerich, J. M., \& Harquail, C. V. (1994). Organizational Images and Member Identification. Administrative Science Quarterly, 39(2), 239-263.

Fazio, R. H. (2001). On the Automatic Activation of Associated Evaluations: An Overview Cognition \& Emotion, 15(2), 115-141.

Fazio, R. H., Sanbonmatsu, D. M., Powell, M. C., \& Kardes, F. R. (1986). On the Automatic Activation of Attitudes. Journal of personality and social psychology, 50(2), 229.

Fuller, J. B., Marler, L., Hester, K., Frey, L., \& Relyea, C. (2006). Construed External Image and Organizational Identification: A Test of The Moderating Influence of Need for Self-Esteem. The Journal of Social Psychology, 146(6), 701-716.

Garrett, R. S., Thurber, J. A., Fritschler, A. L., \& Rosenbloom, D. H. (2006). Assessing the Impact of Bureaucracy Bashing by Electoral Campaigns. Public Administration Review, 66(2), 228-240.

Gendron, Y., \& Spira, L. F. (2010). Identity Narratives Under Threat: A Study of Former Members of Arthur Andersen. Accounting, Organizations, and Society, 35(3), 275-300.

Gilad, S., Maor, M., \& Ben-Num Bloom, P. (2015). Organizational reputation, the content of public allegations, and regulatory communication. Journal of Public Administration Research and Theory, 25(2), 451478.

Gilad, S., Alon-Barkat, S., \& Braverman, A. (2016). Large-Scale Social Protest: A Business Risk and a Bureaucratic Opportunity. Governance, 29(3), 371392.

Goodsell, C. T. (1994). The Case for Bureaucracy. Chatham. NJ: Chatham.

Haslam, S. A., \& Ellemers, N. (2005). Social Identity in Industrial and Organizational Psychology: Concepts, Controversies, and Contributions. International Review of Industrial and Organizational Psychology, 20(1), 39-118. 
Hassan, S., \& Rohrbaugh, J. (2012). Variability in the Organizational Climate of Government Offices and Affective Organizational Commitment. Public Management Review, 14(5), 563-584.

Hvidman, U., \& Andersen, S. C. (2016). Perceptions of Public and Private Performance: Evidence from A Survey Experiment. Public Administration Review, 76(1), 111-120.

Lyons, S. T., Duxbury, L. E., \& Higgins, C. A. (2006). A Comparison of the Values and Commitment of Private Sector, Public Sector, and Para-Public Sector Employees. Public Administration Review, 66(4), 605618.

Mael, F., \& Ashforth, B. E. (1992). Alumni and Their Alma Mater: A Partial Test of The Reformulated Model of Organizational Identification. Journal of organizational Behavior, 13(2), 103-123.

Maor, M. (2015). Theorizing Bureaucratic Reputation. In M. M. Arild Wæraas (Ed.), Organizational reputation in the public sector (pp. 17-36). New York, Abingdon: Routledge

Maor, M., Gilad, S., \& Bloom, P. (2013). Organizational reputation, regulatory talk, and strategic silence. Journal of Public Administration Research and Theory, 23(3), 581-608.

Marvel, J. D. (2015). Public opinion and public-sector performance: Are individuals' beliefs about performance evidence-based or the product of antipublic sector bias? International Public Management Journal, 18(2), 209-227.

Marvel, J. D. (2016). Unconscious Bias in Citizens' Evaluations of Public Sector Performance. Journal of Public Administration Research and Theory, 26(1), 143 158. Mathieu, J. E., \& Zajac, D. M. (1990). A Review and Meta-Analysis of The Antecedents, Correlates, and Consequences of Organizational Commitment. Psychological Bulletin, 108(2), 171-194.

Meyer, J. P., \& Allen, N. J. (1997). Commitment in the Workplace. Thousand Oakes, CA: Sage

Meyer, J. P., Becker, T. E., \& Van Dick, R. (2006). Social Identities and Commitments at Work: Toward an Integrative Model. Journal of organizational Behavior, 27(5), 665-683.

Meyer, J. P., Stanley, D. J., Herscovitch, L., \& Topolnytsky, L. (2002). Affective, Continuance, And Normative Commitment to the Organization: A Meta-Analysis of Antecedents, Correlates, and Consequences. Journal of Vocational Behavior, 61(1), 20-52.

Mizrahi, S., Vigoda-Gadot, E., \& Cohen, N. (2010). Trust, Participation and Performance: The Case of the Israeli National Insurance Institute. Public Management Review, 12(1), 99-126.

Moldogaziev, T. T., \& Silvia, C. (2015). Fostering Affective Organizational Commitment in Public Sector Agencies: The Significance of Multifaceted
Leadership Roles. Public Administration, 93(3), 557575.

Moynihan, D. P., \& Pandey, S. K. (2007). Finding workable levers over work motivation: Comparing job satisfaction, job involvement, and organizational commitment. Administration \& Society, 39(7), 803832.

Olsen, A. L. (2015). Citizen (Dis) Satisfaction: An Experimental Equivalence Framing Study. Public Administration Review, 75(3), 469-478.

Petriglieri, J. L. (2011). Under Threat: Responses to and The Consequences of Threats to Individuals' Identities. Academy of Management Review, 36(4), 641 662.

Pierce, J. L., \& Gardner, D. G. (2004). Self-Esteem within the Work and Organizational Context: A Review of the Organization-Based Self-Esteem Literature. Journal of management, 30(5), 591-622.

Pierce, J. L., Gardner, D. G., Cummings, L. L., \& Dunham, R. B. (1989). Organization-Based SelfEsteem: Construct Definition, Measurement, and Validation. Academy of Management journal, 32(3), 622648.

Rho, E., Yun, T., \& Lee, K. (2015). Does Organizational Image Matter? Image, Identification, and Employee Behaviors in Public and Nonprofit Organizations. Public Administration Review, 75(3), 421-431.

Riketta, M. (2005). Organizational Identification: A Meta-Analysis. Journal of Vocational Behavior, 66(2), 358-384.

Smidts, A., Pruyn, A. T. H., \& Van Riel, C. B. (2001). The Impact of Employee Communication and Perceived External Prestige on Organizational Identification. Academy of Management journal, 44(5), 1051-1062.

Stazyk, E. C., Pandey, S. K., \& Wright, B. E. (2011). Understanding Affective Organizational Commitment: The Importance of Institutional Context. The American Review of Public Administration, 41(6), 603-624.

Tajfel, H. (1982). Social Identity and Intergroup Relations: Cambridge University Press.

Tummers, L. G., \& Knies, E. (2013). Leadership and Meaningful Work in the Public Sector. Public Administration Review, 73(6), 859-868.

Van Dick, R. (2004). My Job Is My Castle: Identification in Organizational Contexts. International Review of Industrial and Organizational Psychology, 19, 171-204.

Yang, K., \& Pandey, S. K. (2009). How Do Perceived Political Environment and Administrative Reform Affect Employee Commitment? Journal of Public Administration Research and Theory, 19(2), 335-360. 


\section{Appendix}

Table 1A. Comparison of the experiment samples

\begin{tabular}{lcccccccc}
\hline \hline & \multicolumn{2}{c}{ Control } & \multicolumn{2}{c}{ Negative signal } & \multicolumn{2}{c}{ Positive signal } & \multirow{2}{*}{ F test } & P-value \\
\cline { 2 - 6 } & Mean & SD & Mean & SD & Mean & SD & & \\
\hline OBSE & .79 & .15 & .78 & .16 & .79 & .16 & .176 & .839 \\
Education & .59 & .21 & .49 & .24 & .50 & .22 & 3.099 & .048 \\
Female & .88 & .33 & .89 & .32 & .94 & .24 & .643 & .527 \\
Age & .62 & .20 & .63 & .21 & .65 & .17 & .390 & .678 \\
Tenure & .50 & .34 & .57 & .34 & .64 & .33 & 2.055 & .132 \\
Org. commitment & .76 & .21 & .74 & .22 & .78 & .15 & .68 & .51 \\
Org. identification & .70 & .25 & .70 & .24 & .71 & .20 & .07 & .93 \\
\hline
\end{tabular}

Table 2A. Descriptive statistics

\begin{tabular}{lccccc}
\hline \hline & $\mathbf{N}$ & Mean & Std & Min & Max \\
\hline OBSE & 164 & .753 & .185 & .111 & 1 \\
Education & 160 & .529 & .371 & 0 & 1 \\
Male & 163 & .098 & .298 & 0 & 1 \\
Age & 163 & .557 & .234 & 0 & 1 \\
Tenure & 158 & .480 & .406 & 0 & 1 \\
Org. commitment & 156 & .760 & .200 & .21 & 1 \\
Org. identification & 159 & .703 & .232 & 0 & 1 \\
\hline
\end{tabular}

\section{Operationalization of variables (Translated back from Hebrew)}

\section{Organizational Identification}

1. When someone criticizes the NSSI, it feels like a personal insult.

2. When talking to family and friends about the NSSI's employees, I tend to say 'we' and not 'them'.

3. When someone praises the NSSI, it feels like a personal compliment.

\section{Affective Organizational Commitment}

1. The NSSI is very meaningful for me.

2. I do not feel a strong sense of belonging to the NSSI (R).

3. I am proud to tell others that I work at the NSSI.

4. The thought that I would be working at the NSSI until retirement pleases me.

Organizational-Based Self-Esteem

1. My opinion is important in this work place.

2. There is faith in my competence in this work place.

3. I am trusted in this work place.

4. There is value to the work that I do here.

5. I am an important part of this work place.

6. I am influential in this work place. 